\title{
Twin pregnancy with a coexisting mole: case report
}

\section{Divya Venkataramani, Sudha Sivakumar*, Preetha Thamilchelvan}

Department of Obstetrics and Gynaecology, Madurai Medical College, Madurai, Tamil Nadu, India

Received: 03 December 2021

Revised: 29 January 2022

Accepted: 31 January 2022

\author{
*Correspondence: \\ Dr. Sudha Sivakumar, \\ E-mail: drsudha.sivakumar@gmail.com
}

Copyright: ( $)$ the author(s), publisher and licensee Medip Academy. This is an open-access article distributed under the terms of the Creative Commons Attribution Non-Commercial License, which permits unrestricted non-commercial use, distribution, and reproduction in any medium, provided the original work is properly cited.

\begin{abstract}
Twin molar pregnancy with a coexisting live fetus and a hydatidiform mole is a rare form of the gestational trophoblastic disease associated with increased risk of obstetrical complications and poor perinatal outcome. Prenatal diagnosis is essential for couple counselling and follow-up in tertiary care centers. The incidence ranges from 1 in 20,000 to 1 in $1,00,000$ pregnancies. Management of such cases is tough because the possibility of fetal survival should be weighed against the risk of complications of molar pregnancy. A case of twin molar pregnancy and a coexisting live fetus diagnosed at 15 weeks using ultrasound is described from obstetrical management to a post molar follow-up.
\end{abstract}

Keywords: Molar, Bhcg, Pregnancy, Ultrasound

\section{INTRODUCTION}

A gestational trophoblastic disease is a group of rare tumors that originates from placental tissue and it can be cured if diagnosed early. ${ }^{1}$ Out of these, the most common is the hydatidiform mole (molar pregnancy). There are 2types: complete mole (diploid, monospermic 46xx)>partial mole (triploid, dispermic 69xxy). Other types of GTD include invasive mole, choriocarcinoma, placental site trophoblastic tumor, twin gestation with a molar pregnancy. ${ }^{1,2}$ Twin gestation with a molar pregnancy is one of the rarest forms of presentation seen, and its management is complex because of the possibility of fetal survival should be weighed against the risk and its outcome. ${ }^{3}$

\section{CASE REPORT}

A 19-year-old teenage primi with a history of spotting for the past one week and excessive vomiting was admitted to the Gynecology Department, Government Rajaji Hospital Madurai, on July 2021
Case of spotting per vaginum, lower abdominal pain, excessive vomiting.

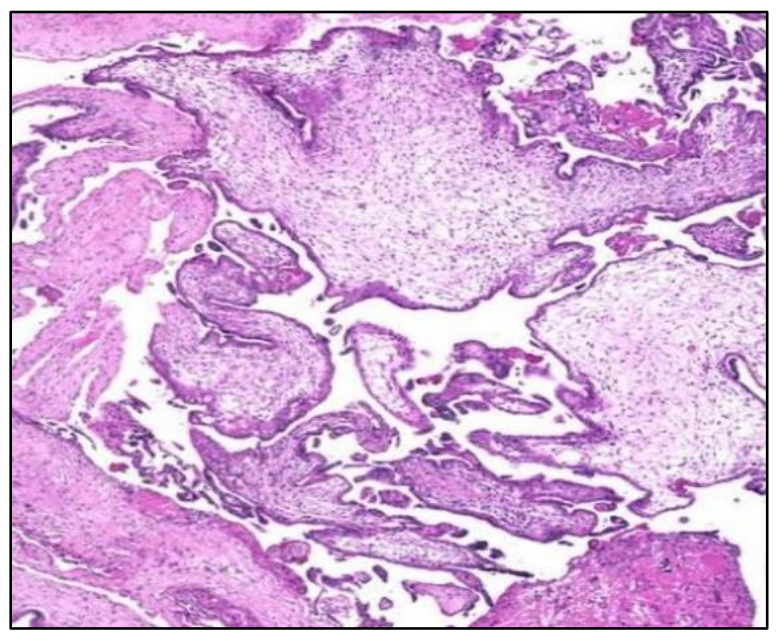

Figure 1: Histopathology suggestive of complete hydatidiform mole with hydropic villi and trophoblastic proliferation. 
History of hyperthyroidism diagnosed one month back, started on T. carbimazole.

Attained menarche at 13 years of age, has regular cycles.

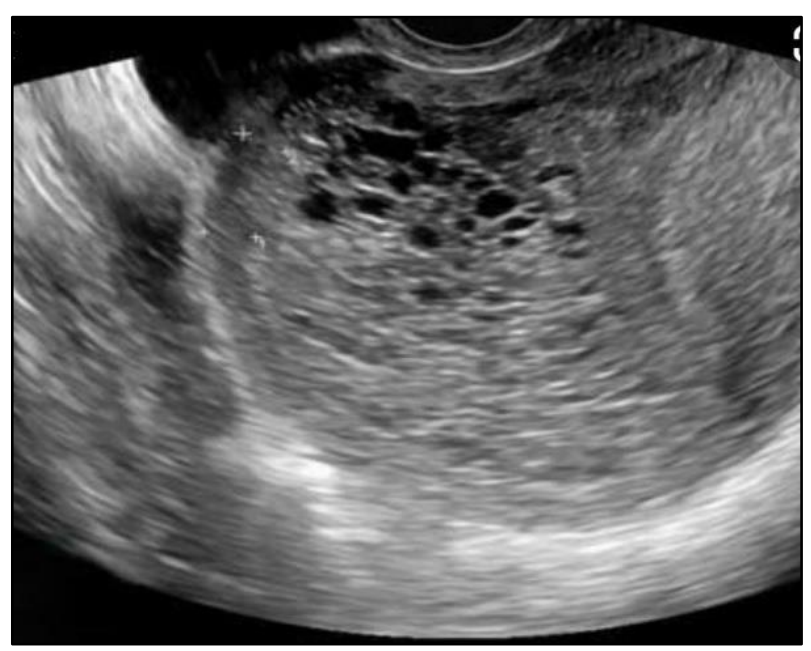

Figure 2: A two-dimensional (2D) ultrasound scan shows a uterus filled with heterogeneous echogenic material suggestive of a molar pregnancy.

On general examination, the patient was anemic and systemic examination was unremarkable.

PR:89/mt, BP: 120/70 mmhg. Bilateral lung field clear.

P/A: Uterus more than the period of gestation (twin/molar] 18-20 weeks, not acting, Foetalparts+, Foetal Heart rate+, Per vaginum examination: cervix pointing downwards, uterus 18 weeks size, OS closed, fornices free, blood on examining finger.

On admission, her BHCG: 6,25, $077 \mathrm{miu} / \mathrm{ml}$. Investigations: $\mathrm{Hb}: 8.5 \mathrm{gm}$, renal and liver parameters normal, urine routine- nil.

Thyroid profile (TSH) and chest X-ray taken- normal study. A two-dimensional ultrasound scan revealed a twin gestation with molar pregnancy and normal viable fetus in another sac of GA 15 weeks and left adnexa replaced by multiple cystic lesions with septations measuring $9.4 \times 6.3$ $\mathrm{cm}$ with peripheral vascularity (B/L theca lutein cysts).

Anesthetic assessment obtained.

Anemia correction with two packed cell transfusions was administered and planned for suction and curettage under general anesthesia. Blood and blood products were crossmatched and reserved. Under General anesthesia, parts were painted and draped, the patient in lithotomy position, she expelled the first twin which was degenerated molar placenta, followed by expulsion of the second twin which was a fresh dead born male fetus weighing $550 \mathrm{gms}$ with the minimally degenerated placenta.
Under USG guidance, suction and curettage was done, and the specimen was sent for histopathology. Analysis revealed molar pregnancy, immunohistochemistry staining for P57- negative.

The patient had an uneventful postnatal period and was transferred to the medical oncology department for GTD registry and postnatal follow up.

Oral contraceptives were started $48 \mathrm{hrs}$ post evacuation and to follow up once a week with serum BHCG reports

\section{Follow up}

Day 2 BHCG: 11,453 $\mathrm{mIU} / \mathrm{ml}$, day 14 BHCG: 6507 $\mathrm{mIU} / \mathrm{ml}$, day 21 BHCG: $1025 \mathrm{mIU} / \mathrm{ml}$, day 28 BHCG: 543 $\mathrm{mIU} / \mathrm{ml}$. Shows a declining trend, and the patient was asked to follow up monthly once for the next six months, and contraception advised. Beta HCG after 1 month: <5 $\mathrm{mIU} / \mathrm{ml}$.

\section{DISCUSSION}

The gestational trophoblastic disease forms a group of disorders that includes complete and partial molar pregnancies through to the malignant conditions of invasive mole, choriocarcinoma, and very rare placental site trophoblastic tumor. Molar pregnancies can be subdivided into complete moles and partial moles based on genetic and histopathological features. Complete moles are diploid and androgenic in origin, with no evidence of fetal tissue. Complete moles (75\%-80\%) arise due to duplication of a single sperm following fertilization of an empty ovum. Some complete moles (20\%-25\%) can arise after the dispermic fertilization of an empty ovum. In partial mole, there is usually evidence of foetus or foetal red blood cells. ${ }^{1}$

Twin gestation with a coexisting fetus and a molar pregnancy is highly a rare variation of molar pregnancy. It accounts for 0.005 to $0.01 \%$ of all pregnancies and derives from dispermic fertilization of a normal haploid oocyte and produce a tripletset of chromosomes. Increased incidence is due to greater use of assisted reproductive technologies. ${ }^{1,2}$ Risk factors include previous history of molar pregnancy, extremes of age, and consanguineous marriage. Symptoms like hyperemesis gravidarum, heavy bleeding from the vagina, excessive uterine enlargement, and early failed pregnancy. Rare presentations are earlyonset preeclampsia, hyperthyroidism, abdominal distension due to theca lutein cysts. Very rarely can present as acute pulmonary edema and seizures. ${ }^{1,3}$

The outcome of a normal pregnancy with a complete coexisting mole is poor, with approximately a $25 \%$ chance of achieving a live.

Birth, 40 percent risk of early fetal loss,36 percent risk of premature delivery, and20 percent risk of preeclampsia. ${ }^{1}$ 
Interruption of pregnancy is due to congenital anomalies like triploidy of fetus and severe IUGR due to limited normal functioning placental circulation. Women must be counseled regarding maternal and fetal complications like lateabortion, malpresentation, preterm labor, vaginal bleeding, persistent GTN, severe anemia in the fetus, hyperthyroidism, hypertensive disorder of pregnancy, pulmonary edema, and thromboembolic phenomena. ${ }^{1,2}$

Therefore, a pregnancy needs to be followed with an ultrasound assessment of fetal growth and anatomy. The use of ultrasound in early pregnancy has led to the earlier diagnosis of molar pregnancy. ${ }^{3}$ The majority of histologically proven moles are associated with an ultrasound diagnosis of delayed miscarriage/anembryonic pregnancy. Accuracy of ultrasound for diagnosis $[<14$ weeks $=35-40 \%$ accuracy $][>14$ weeks $=60 \%$ accuracy $]$.

Later the gestational age easier is the diagnosis.

Ultrasound diagnosis of partial molar pregnancy is more cystic spaces in the placenta, and a ratio of transverse to an anteroposterior dimension of gestation sac of greater than 1.5 is required for the reliable diagnosis of partial molar pregnancy..$^{1-3}$

Estimation of HCG levels may be of value in diagnosing molar pregnancies, HCG levels more significant than two multiples of the median.

Suction and curettage are the method of choice for evacuation of complete molar pregnancies. ${ }^{4}$ Suction curettage is the method of evacuation for partial molar pregnancies, except when the size of the fetal parts deters the use of suction curettage, and the medical evacuation can be used. Preparation of cervix just immediately prior to evacuation is safe. Use of oxytocin infusion prior to the completion of evacuation is not recommended. If the woman experiences significant hemorrhage prior to evacuation, surgical evacuation to be expedited and need for oxytocin infusion weighed up against the risk of tumor embolization and the histological assessment of material obtained from the medical/surgical management of all failed pregnancies is recommended to exclude trophoblastic neoplasia. ${ }^{3,5}$

Genetic counselling and prenatal invasive testing for fetal karyotype to be offered to the patient, when it is unclear if the pregnancy is a complete mole with a coexisting normal twin or a partial mole. ${ }^{1,2}$ Follow-up of every case is mandatory and should be registered in the GTN registry. Follow-up of the cases after GTD is increasingly individualized. ${ }^{4}$ If $\mathrm{HCG}$ has reverted to normal within 56 days of pregnancy, follow-up is for six months of uterine evacuation. If HCG has not reverted to normal within 56 days of the pregnancy event, the follow-up would be for six months from the normalization of HCG, and follow-up is advised for 6-8 weeks from the pregnancy event. Conception is not advised for one year after treatment. The barrier methods are contraception of choice till HCG levels normalize, followed by oral contraceptive pills. ${ }^{1-3}$

Single- agent/multiagent chemotherapy is given for GTN based on the FIGO scoring system.

\section{CONCLUSION}

Twin gestation with a coexisting mole is a rare form of gestational trophoblastic disease. Early booking of pregnant women to antenatal care and routine firsttrimester USG has made a diagnosis earlier and for better obstetrical management. Patients with BHCG levels $>1,00,000$, age $>40$ years, large for dates and bilateral large theca lutein cysts are at high risk of developing GTN and should be followed up weekly.

\section{Funding: No funding sources \\ Conflict of interest: None declared \\ Ethical approval: Not required}

\section{REFERENCES}

1. Management of Gestational Trophoblastic Disease, Green Top Guidelines No.38, BJOG. An International J Obstet Gynaecol. 2020;128(3):1-27.

2. Johnson C, Davitt C, Harrison R, Cruz M. Expectant management of a Twin pregnancy with Complete hydatidiform mole and coexistent normal foetus. Case Rep Obstet Gynaecol. 2019:1-34.

3. Braga A, Obeica B, Werner H, Sun SY, Amim Y, Filho JR et al. A twin pregnancy with a hydatidiform mole and a coexisting live foetus: prenatal diagnosis, treatment and follow-up. J Ultrason. 2017;17:299305.

4. Sukasi M, Suwanrath C, Kor-Anantakul O, Geater A, Hanprasertpong T, Atjimakul T, Pitchatechaiyoot A.Complete hydatidiform mole with co-existing fetus: Predictors of live birth. Eur J Obstet Gynecol Reprod Biol. 2017;212:1-8.

5. Duggan P, Lung Y, Neesham D, Nally OM, Garrett A, Brand A et al. The Management of Gestational trophoblastic disease. Ranzcog. 2013;31:1-17.

Cite this article as: Venkataramani D, Sivakumar S, Thamilchelvan P. A two-dimensional (2D)

ultrasound scan shows a uterus filled with heterogeneous echogenic material suggestive of a molar pregnancy. Int J Reprod Contracept Obstet Gynecol 2022;11:976-8. 